RESENHA

Bookreview

\title{
MUDANÇAS NA NATUREZA DA RELAÇÃO BRASIL ESTADOS UNIDOS DURANTE E APÓS A SEGUNDA GUERRA MUNDIAL ${ }^{1}$
}

Cintia Vieira Souto ${ }^{2}$

Em 2012, a FUNAG publicou a íntegra da tese de doutorado de Gerson Moura, Relações Exteriores do Brasil: 1939-1950. Mudanças na natureza da relação Brasil Estados Unidos durante e após a Segunda Guerra Mundial, defendida há trinta anos, em 1982, no University College of London. É amplamente conhecido o trabalho do autor, Autonomia na Dependência, de 1980, que introduziu nos estudos históricos e de política externa as expressões "barganha nacionalista" e "equilíbrio pragmático". Agora, diante da tese de Moura, percebemos o seminal texto de 1980 como introdução a um estudo maior.

Os três primeiros capítulos de Relações Exteriores do Brasil: 1939-1950 são uma versão ampliada de Autonomia na Dependência. No capítulo I, Introdução, Moura discorre a respeito das mudanças na América Latina e no Brasil na década de 1930. Na América Latina, ocorria o declínio da influência britânica e o crescimento da influência alemã e norte-americana, que prestes a constituírem sistemas de poder antagônicos, disputavam espaços na região. Os Estados Unidos com a política de Boa Vizinhança de Roosevelt subordinava questões econômicas às questões políticas estratégicas. $\mathrm{O}$ objetivo estadunidense era garantir a colaboração política e o alinhamento dos países

\footnotetext{
${ }^{1}$ MOURA, Gerson. Relações Exteriores do Brasil: 1939-1950. Mudanças na natureza da relação Brasil Estados Unidos durante e após a Segunda Guerra Mundial. Brasília: FUNAG, 2012.

${ }^{2}$ Doutoranda do PPGEEI-UFRGS. Professora da FAPA-RS. Email: cintia.souto@ gmail.com.
} 


\section{Conjuntura Austral}

latino-americanos à liderança norte-americana. Isso explica, por exemplo, a tolerância do governo Roosevelt com o comércio compensado com a Alemanha acertado a partir de 1936. O governo norte-americano firmara um acordo de comércio com o Brasil em 1935 e houve pressão para que o comércio com a Alemanha fosse encerrado. Todavia, essas pressões assumiam mais a forma de recomendações do que de pressões efetivas. A partir de 1938, com um cenário de guerra se avizinhando, a Boa Vizinhança passou a incluir objetivos militares. Com a eclosão da guerra e a com a possibilidade de um ataque alemão a partir do norte da África, Washington necessitava de bases militares no território brasileiro, especialmente no Nordeste.

A Alemanha, além das facilidades do comércio compensado, exercia importante influência política e ideológica por meio de diversos canais: embaixadas, consulados, escolas, clubes, etc., aproveitando o expressivo contingente de população de origem alemã no Brasil. Sem falar no prestigio que o regime nazista desfrutava junto a setores da sociedade e do Exército, inclusive membros do alto escalão.

No Brasil, o período em questão é de consolidação do Estado Novo. A partir de 1937, duas questões ocupavam o governo Vargas: a necessidade de investimentos para a construção de uma indústria siderúrgica e a modernização das Forças Armadas. Nos círculos decisórios havia grande divisão ideológica com partidários do livre comércio versus comércio compensado, liberais versus nacionalistas, "pró-Eixo" versus "próEstados Unidos". O Ministério das Relações Exteriores era organizado em moldes liberais mais tradicionais e era, de forma geral, alinhado com posições norte-americanas e britânicas. Osvaldo Aranha, Chanceler entre 1938 e 1944, era um dos principais entusiastas dos interesses norte-americanos. Já o Ministro do Exército, Eurico Gaspar Dutra e o Chefe do Estado Maior, Pedro Aurélio de Góis Monteiro, eram admiradores do Eixo. Essas divisões permitiram que Getúlio Vargas assumisse um papel privilegiado, como uma espécie de árbitro, explorando as oportunidades criadas pela concorrência dos dois sistemas de poder em ascensão. "Em geral, a melhor maneira de descrever a política externa do Brasil na década de 1930 é como uma oscilação entre uma grande potência e a outra em termos comerciais, políticos e militares. Esta política de equilíbrio pragmático entre a Alemanha e os Estados Unidos produziu uma série de 


\section{Conjuntura Austral}

benefícios comerciais e aumentou o poder de barganha do Brasil nos anos vindouros" (MOURA, 2012, p. 51).

No capítulo II, Anos de Neutralidade (1939-1941), Gerson Moura descreve o período no qual o Brasil obteve os maiores ganhos com o equilíbrio pragmático. $\mathrm{O}$ governo brasileiro manteve as suas metas estratégicas - industrialização do país e reequipamento das forças armadas - apesar as consequências econômicas, sociais e políticas acarretadas pelo início da guerra na Europa. O comércio com a Alemanha cessou em 1940 com o bloqueio naval britânico. Mas o declínio do comércio não significou a perda do prestígio político do Reich no Brasil. Aliás, um dos efeitos do bloqueio foi uma onda de sentimentos antibritânicos nos círculos militares brasileiros. Vargas adotou uma posição de neutralidade em relação à guerra, tentando manter o equilíbrio. A partir de 1940, os Estados Unidos lançou uma ofensiva econômica, política e cultural sobre a América Latina, sendo que o Brasil era um dos principais alvos. Uma das principais medidas foi a criação do Birô do Coordenador de Assuntos Interamericanos (OCIAA - Office of the Coordinator of Inter-American Affairs) em 16 de agosto de1940, sob a liderança de Nelson Rockefeller. O OCIAA era subordinado ao Conselho de Defesa Nacional e tinha objetivo expresso de eliminar a influência do Eixo na América Latina através de ações econômicas, culturais, de saúde, etc. Entre agosto e setembro de 1940, foi fechado em Washington o acordo para a construção de Volta Redonda. Os recursos seriam fornecidos pelo Eximbank e a assistência técnica providenciada por empresas privadas estadunidenses.

O ponto mais complexo da colaboração Brasil Estados Unidos foi o militar. Isso se explica, em parte, pela simpatia que parte do Exército Brasileiro tinha pelo Eixo, inclusive no primeiro escalão do governo. Em 1941, as relações entre os dois países tinham melhorado em todos os níveis, com exceção do militar. Os americanos desejavam uma "colaboração passiva" dos militares brasileiros, com a cessão de bases e aeroportos que seriam operados por militares norte-americanos. Esperava-se que os exércitos dos aliados subordinados se ocupassem da manutenção da ordem interna, enquanto o exército estadunidense defenderia o continente. Os militares brasileiros não 


\section{Conjuntura Austral}

aceitaram esse papel e impuseram toda a sorte de obstáculos ao projeto da grande potência.

O capítulo III, Da Neutralidade à Guerra (janeiro a agosto de 1942), enfoca os oitos meses nos quais o Brasil abandonou o equilíbrio pragmático e embarcou em uma sólida aliança com os Estados Unidos. Na Conferência do Rio em Janeiro de 1942, o Brasil rompeu relações com o Eixo. Entre fevereiro e março, o ministro da Fazenda Souza Costa esteve em Washington quando foram assinados com o governo dos Estados Unidos acordos militares e econômicos. Em maio, um acordo secreto políticomilitar criou duas comissões militares mistas para planejar a defesa do território brasileiro. Finalmente, em agosto, após o afundamento de cinco navios mercantes nacionais, o Brasil declarou guerra à Alemanha e à Itália.

$\mathrm{Na}$ Conferência do Rio, o governo norte-americano buscava a unanimidade na ruptura com o Eixo. A Argentina e o Chile se opuseram. O Chile temia ataques japoneses à sua costa, ao passo que o governo argentino dependia de um equilíbrio doméstico delicado, com influências nacionalistas nas forças armadas obstaculizando qualquer aproximação aos aliados.

Os acordos militares resolveram em parte os dois impasses do ano anterior: a questão do fornecimento de armamento requisitado pelos militares brasileiros e a questão da defesa do Nordeste. Moura destaca que "a resistência interna particularmente militar - ao alinhamento com os Estados Unidos constituiu um elemento importante das negociações, já que a estratégia estadunidense necessitava da colaboração militar brasileira. O governo brasileiro usou a resistência dos militares como moeda de troca, podendo assim garantir que as forças armadas brasileiras então fossem as mais bem equipadas da América Latina" (MOURA, 2012, p. 117-118).

No capítulo IV, Os anos da guerra (agosto de 1942-1945), o autor apresenta a formação e o engajamento de uma Força Expedicionária Brasileira (FEB) no teatro de guerra europeu, como um desdobramento do equilíbrio pragmático. A FEB, que não era desejada nem pelo governo norte-americano, nem pelo britânico, foi um projeto desenhado para fortalecer as forças armadas brasileiras e dar ao Brasil uma posição de destaque na América Latina como "aliado especial” dos Estados Unidos. 


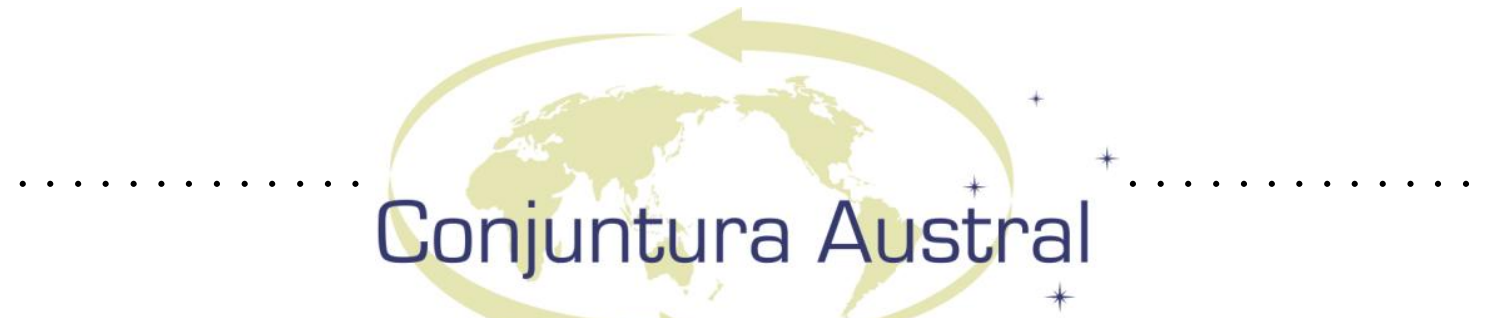

O governo Vargas percebeu claramente a perda de importância estratégica do Brasil com a invasão do norte da África pelos aliados em novembro de 1942. Roosevelt contornava as demandas brasileiras com lisonjas, como o encontro com Vargas em Natal, em janeiro de 1943, no retorno da Conferência de Casablanca. Foi nesse momento que os militares passaram a insistir na participação direta na guerra. A moeda de troca foi a garantia de manutenção das bases militares no Norte e no Nordeste sob controle norte-americano no pós-guerra. Em 5 de maio de 1943, foi decidido o envio da FEB para o exterior. A força com 25 mil homens lutou na Itália entre julho de 1944 e fevereiro de 1945. Chegou o período no qual a capacidade brasileira de extrair benefícios do seu alinhamento aos Estados Unidos declinou.

O capítulo V, Os anos pós-guerra (1946-1950), trata das mudanças que o pósguerra, o início da guerra fria, o fim do Estado Novo e a redemocratização trouxeram às relações Brasil-Estados Unidos. Moura mostra que apesar das mudanças na política externa não terem sido expressivas - Dutra fora ministro de Vargas e o seu Ministro das Relações Exteriores era João Neves da Fontoura, amigo do presidente deposto - a implementação dessa política foi bastante diversa. O alinhamento com Estados Unidos de Vargas era um instrumento da política externa brasileira, ao passo que com Dutra esse alinhamento se tornou o objetivo desta política tanto em termos bilaterais, quanto multilaterais. Um bom exemplo foi o embate na ONU entre Osvaldo Aranha, chefe da delegação brasileira, e Raul Fernandes, Ministro das Relações Exteriores a partir de 1946. Aranha, da escola "varguista" percebia a possibilidade de jogar com as brechas nas discordâncias das grandes potências, ao passo que Fernandes considerava dever da delegação brasileira votar sempre com os Estados Unidos.

No plano ideológico observa-se a linguagem do pan-americanismo, que fora tão eficiente no período da guerra, adaptar-se à guerra fria. Agora era o "mundo livre" em oposição à "cortina de ferro", a "civilização cristã ocidental" em oposição ao “comunismo ateu". O Brasil de Dutra se considerava representante desse mundo livre na América Latina, julgando que isso lhe traria vantagens junto ao governo norteamericano. 


\section{Conjuntura Austral}

A riqueza de informações levantadas em fontes brasileiras, norte-americanas e britânicas, aliada ao rigor analítico, fazem da tese de Gerson Moura leitura obrigatória para todos os estudiosos de política externa brasileira. $\mathrm{O}$ autor destaca na introdução e na conclusão que sua preocupação principal era estudar as condições que permitem a um aliado subordinado, num dado sistema de poder, exercer alguma capacidade de ação independente. Ele acerta ao mostrar, no período estudado, as limitações e as possibilidades, apontando-as e analisando-as.

A leitura do texto será mais produtiva ainda, se feita em conjunto com Autonomia na Dependência. Um ponto interessante é que no texto de 1980 Moura se preocupa muito mais em esclarecer os conceitos e a hipótese com os quais trabalha. Isso está explícito nos dois primeiros capítulos do livro. Em Relações Exteriores do Brasil: 1939-1950 essas questões teóricas estão diluídas no texto, o que faz de Autonomia um trabalho mais didático. Contudo, somente na tese, Moura teve espaço para discutir a enorme quantidade de fontes de que dispunha. Valoriza muito o trabalho a discussão das fontes britânicas. A Inglaterra via, quase como um observador externo, a aproximação entre Brasil e Estados Unidos, se posicionando sempre no sentido de diminuir o declínio de sua própria influência. É muito interessante ter acesso às observações dos diplomatas britânicos que, em muitas situações, tinham maior clareza em relação ao que estava ocorrendo do que os norte-americanos e brasileiros.

$\mathrm{Na}$ apresentação, Letícia Pinheiro destaca que Gerson Moura fez sua pesquisa na época do pragmatismo responsável de Ernesto Geisel e do universalismo de João Figueiredo, período no qual se buscavam explicações para o comportamento autônomo do Brasil no contexto da détente e da crise internacional da época. Certamente esse foi um dos motivos de seu interesse pelo período da guerra e do pós-guerra, a busca da autonomia num período igualmente difícil. Assim, Relações Exteriores do Brasil: 1939-1950 é também um estudo sobre o Brasil das décadas de 1970 e 1980. 